\title{
Effect of education on nurse's knowledge about low cardiac output syndrome identification and management
}

\begin{abstract}
Background: Low cardiac output syndrome (LCOS) refers to a decrease in cardiac output that is due to transient myocardial dysfunction. Low cardiac output syndromes (LCOS) is the most common post cardiac surgery syndrome in both adults and Peads, with the prevalence rate ranging from 3 to $45 \%$ in critical care unit. Studies have shown that lack of knowledge about warning signs of LCOS among nurses in critical care areas are may be an obstacle in early identification and management of LCOS. Therefore, the purpose of this project is to identify whether two hour teaching module is effective to increase nurse's knowledge about LCOS identification and management among nurses working in cardiac intensive care unit.
\end{abstract}

Method: This study was conducted at a private tertiary care teaching hospital in Karachi, Pakistan. Single group pre-test/post-test design was used. Twenty- six cardiac intensive care unit nurses were included in the study. The knowledge of nurses was assessed before and after the education intervention. The demographic data sheet was used to collect relevant information from the participants. Knowledge was assessed through a self-developed validated tool, consisting of multiple-choice questions. The difference in knowledge was analyzed through paired $t$ test.

Result: Knowledge scores of participants increased significantly after the educational intervention in the post- test.

Conclusion: The two- hour teaching intervention has significantly improved nurse's knowledge about LCOS. Among healthcare providers, nurses are the one who spent most of the time with patients after cardiac surgery. Therefore, it is the responsibility of stakeholders to educate their nurses for better patient care. Further, nurses are also accountable for their own learning and growth.

Keywords: low cardiac output syndrome, knowledge, practic
Volume 3 Issue 2 - 2017

\author{
Hina Nizar Karim \\ Department of Nursing and Midwifery,Aga Khan University, \\ Pakistan
}

Correspondence: Hina Nizar Karim, Department of Nursing and Midwifery, Aga Khan University, Pakistan,

Email hina.nizar.mnI4@student.aku.edu

Received: October 31, 2016 | Published: July 07, 2017

\section{Introduction}

Low cardiac output syndrome (LCOS) refers to a decrease in cardiac output that is due to transient myocardial dysfunction. Factors contributing to Low cardiac output syndrome are hypothermia, reperfusion injury, pericardial tamponade, release of inflammatory mediators and aortic cross clamp leading to myocardial ischemia. ${ }^{1}$ The potential complications of low cardiac output syndrome results in increase morbidity and mortality of heart surgery patients, increase hospital stay, increase risk of hospital-acquired infection and increase in resource utilization. ${ }^{1}$ LCOS is a transient medical condition but if could-not picked up early then chances of mortality increases. On the other hand, decrease cardiac output is a nursing diagnosis introduced by national conference group on the classification of nursing diagnosis in $1980 .^{2}$ The aim of this nursing diagnosis is to help nurses improve their critical care knowledge and better understand the clinical signs and early management of patients who have decrease cardiac output.

Low cardiac output syndromes (LCOS) is the most common post cardiac surgery syndrome in both Adults and Peads, with the prevalence rate ranging from 3 to $45 \%$ in critical care unit. ${ }^{3}$ Globally, the incidence of LCOS has reached up to $38 \%$ in adults and is considered one of the largest cause of mortality after coronary artery bypass grafting. ${ }^{4}$
The incidence of low cardiac out syndrome post- pediatric congenital cardiac surgery is $25 \% .{ }^{5}$ A retrospective data collected in Aga Khan University Hospital, Karachi (2016), showed that prevalence of LCOS in post - cardiac congenital surgical children is approximately $14 \%$.

Globally studies have shown that lack of knowledge about warning signs of LCOS among nurses in critical care areas are may be an obstacle in early identification and management of LCOS. ${ }^{2}$ Therefore, the purpose of this study is to identify whether 2-hour teaching module is effective to increase nurse's knowledge about LCOS identification and management who are working in cardiac intensive care unit.

\section{Methods}

The teaching was conducted by using a single group pre-test and post- test in cardiac intensive care unit (CICU) of tertiary care center, at Karachi, Pakistan. The CICU include six beds for adult and four beds for pediatrics post- operative cardiac surgical patients. The single group includes twenty six (26) nurses and nurse technician of CICU. A simple and concise demographic data sheet was used to collect nurses and technician information. It includes gender, years of experience, qualification or any other specialized diploma or certificate. The demographic profile of participants is attached in the Table 1. 
Table I Demographic variables of the study participants $n=(26)$

\begin{tabular}{|c|c|c|}
\hline Variables & Frequency (n) 26 & $\%$ \\
\hline \multicolumn{3}{|l|}{ Sex } \\
\hline Male & 20 & 78 \\
\hline Female & 6 & 22 \\
\hline \multicolumn{3}{|l|}{ Age } \\
\hline $22-32$ & 16 & 61 \\
\hline $33-43$ & 5 & 19 \\
\hline$>44$ & 3 & 11 \\
\hline \multicolumn{3}{|l|}{ Designation } \\
\hline Nursing Intern & 2 & 7 \\
\hline Registered Nurse & 16 & 61 \\
\hline Critical Care Nurse & 1 & 3 \\
\hline Senior Critical Care Nurse & 1 & 3 \\
\hline Critical Care Technician & 6 & 23 \\
\hline Senior Critical Care Technician & 1 & 3 \\
\hline \multicolumn{3}{|l|}{ Employment Status } \\
\hline Part time & 26 & 100 \\
\hline Full time & 0 & - \\
\hline \multicolumn{3}{|l|}{ Nursing qualification } \\
\hline Diploma & 9 & 34 \\
\hline $\mathrm{BSc} N$ & 8 & 30 \\
\hline \multicolumn{3}{|l|}{ Critical care qualification } \\
\hline No qualification & 12 & 46 \\
\hline Critical care certificate & 7 & 26 \\
\hline $\begin{array}{l}\text { Post Graduate Diploma (critical care / } \\
\text { DIPCARD) }\end{array}$ & 7 & 26 \\
\hline \multicolumn{3}{|l|}{ Years of experience as a nurse } \\
\hline$<1$ & 4 & 15 \\
\hline 5-Jan & 11 & 42 \\
\hline 10-Jun & 3 & 11 \\
\hline 15-Nov & 0 & 0 \\
\hline$>15$ & 1 & 3 \\
\hline \multicolumn{3}{|l|}{ Years of experience as a technician } \\
\hline$<1$ & 0 & 0 \\
\hline $1-5$ & 1 & 3 \\
\hline $6-10$ & 2 & 7 \\
\hline $11-15$ & 0 & 0 \\
\hline$>15$ & 3 & 11 \\
\hline \multicolumn{3}{|l|}{$\begin{array}{l}\text { Cardiac surgical intensive care } \\
\text { experience }\end{array}$} \\
\hline$<1$ & 7 & \\
\hline $1-5$ & 10 & \\
\hline $6-10$ & 5 & \\
\hline$>10$ & 2 & \\
\hline \multicolumn{3}{|l|}{ Life saving course } \\
\hline BLS & 26 & 100 \\
\hline ACLS & 12 & 46 \\
\hline PALS & 5 & 19 \\
\hline NRP & 3 & II \\
\hline
\end{tabular}

The pre test and post test questionnaire included same eight questions. The questions were set to assess their knowledge and practices related to LCOS. It includes clinical based scenarios and some recalling questions related to cardiac physiology.

\section{Results}

The mean age of participants was between 22-32 years Table 1 . Males were predominant (78\%) while females were only $22 \%$. The various nursing degree were represented as follow: Diploma in nursing $100 \%$, Post RN Bachelors 26\%, Generic B.Sc N 11\% and Critical care technicians $26 \%$. Of those with Post RN Bachelors, 26\% had additional specialization in Diploma in Cardiac Nursing. As mandated by the hospital policy $100 \%$ nursing staff were BLS certified, $46 \%$ were also ACLS certified and only $19 \%$ were PALS certified. The total years of cardiac critical care unit experience was also calculated and it was between 5-10 years.

The educational intervention significantly improved the knowledge level of the participants regarding identification and management of LCOS. The results of the pre-test highlighted that majority of the nurses had a significantly low level of knowledge regarding warning signs and management of Table 2 clearly shows there was a difference in mean from 58.41 to 81.25 in post -test. Thus, mean post- test score are significantly higher than the mean score of pre test. In addition, $p$ value is .0000 , which is highly significant, and it reflects that education intervention has improved nurse's knowledge. The overall positive change in the nurse's knowledge after the teaching module reflects that education can bring about change in knowledge level. The effectiveness of teaching or training in increasing knowledge of health care professionals is also supported by other studies. ${ }^{6}$

Table 2 Paired $t$ test of pre and post teaching session

\begin{tabular}{lllll}
\hline & Mean & N & Std. deviation & Std. error mean \\
\hline Pretest & 58.4135 & 26 & 12.49279 & 2.45004 \\
Posttest & 81.25 & 26 & 18.45603 & 3.61953
\end{tabular}

\section{Discussion}

Low cardiac output syndrome is a complex clinical problem after cardiac surgery with the incidence of $15 \%$ in America. The incidence is higher in Pakistan and other Asian countries because of limited technology and skills. ${ }^{1}$ It is also been observed and evident in pre test and post- test result that there is a need for implementation of teaching on LCOS. Further, there is a great need to do valuable research on LCOS in our country as we lack resources, latest technology and work force. The M.Sc N students are in a better position to move nursing research from publication to bedside teaching and to evaluation Table 3.

\section{Strengths and limitations}

This study has much strength. Firstly, it is a first study in Pakistan who has explored and discusses LCOS knowledge among healthcare providers in Pakistan. Secondly, this study provides opportunity to nurses and technician to upgrade their knowledge and improve their practices about LCOS. Further, many teaching materials were formulated and LCOS identification and management algorithm were pasted on every bedside of CICU for nurse's quick reference. Moreover, all the teaching material was handover to CICU, clinical nurse instructor for future teaching sessions. 
Table 3 Paired samples test

\begin{tabular}{|c|c|c|c|c|c|c|c|c|}
\hline \multirow[t]{3}{*}{ Pretest posttest } & \multicolumn{5}{|c|}{ Paired differences } & \multirow[t]{3}{*}{$\mathbf{t}$} & \multirow[t]{3}{*}{ df } & \multirow[t]{3}{*}{ Sig(2-failed) } \\
\hline & \multirow[t]{2}{*}{ Mean } & \multirow{2}{*}{$\begin{array}{l}\text { Std. } \\
\text { deviation }\end{array}$} & \multirow{2}{*}{$\begin{array}{l}\text { Std. error } \\
\text { mean }\end{array}$} & \multicolumn{2}{|c|}{$\begin{array}{l}95 \% \text { confidence interval of } \\
\text { the difference }\end{array}$} & & & \\
\hline & & & & Upper & Lower & & & \\
\hline & -22.83654 & 23.04495 & 4.51949 & -32.14460 & -13.52848 & -5.053 & 25 & .000 \\
\hline
\end{tabular}

One of the limitation in this project was, not all the nurses attended the in-service sessions. As few were on leaves and four nurses are part time. Those who could not attend were asked to read the bedside template of LCOS and ask the unit clinical nurse instructor for any query. Another limitation of the project was limited number of inservice sessions offered due to venue constraints. Therefore, M.Sc N student conducted bedside teaching. It was little difficult to spare staff for bedside teaching as they were busy in their clinical areas. ${ }^{7-11}$

\section{Conclusion and recommendations}

Results of this clinical project have demonstrated that nurses working in cardiac critical care unit are not sufficiently knowledgeable regarding LCOS identification and management. This lack of knowledge may be the result of decrease clinical knowledge or theoretical knowledge learned in school of nursing or they had less working experience in CICU. Whereas, education intervention has improved nurses knowledge about LCOS as evident in post test. Among healthcare providers, nurses are the one who spent most of the time with patients after cardiac surgery. If nurses were poorly prepared then un- identification of LCOS would lead to increase mortality. Therefore, it is the responsibility of stakeholders to educate their nurses for better patient care. Further, nurses are also accountable for their own learning and growth.

\section{Acknowledgements}

None.

\section{Conflict of interest}

The author declares no conflict of interest

\section{References}

1. Kumar G, Iyer PU. Management of perioperative low cardiac output state without extracorporeal life support: What is feasible. Ann Pediatr Cardiol. 2010;3(2):147-158.
2. Brandão SMG, Altino DM, Lopes JDL. Defining characteristics of decreased cardiac output: a literature review. Int J Nurs Terminol Classif. 2011;22(2):92-102.

3. Wessel DL. Managing low cardiac output syndrome after congenital heart surgery. Crit Care Med. 2001;29(10):S220-230.

4. Nogueira JRC, Ferraz PE, Figueiredo OJ, et al. Risk factors for low cardiac output syndrome after coronary artery bypass grafting surgery. Rev Bras Cir Cardiovasc. 2012;27(2):217-223.

5. Jones B, Hayden M, Fraser JF, et al. Low cardiac output syndrome in children. Current Anaesthesia \& Critical Care. 2005;16(6):347-358.

6. Yousefi H, Nahidian M, Sabouhi F. Reviewing the effects of an educational program about sepsis care on knowledge, attitude, and practice of nurses in intensive care units. Iran J Nurs Midwifery Res. 2012;17(2 Supp11):S91-S95.

7. André AC, DelRossi A. Hemodynamic management of patients in the first 24 hours after cardiac surgery. Crit Care Med. 2005;33(9):2082-2093.

8. Beke DM, Braudis NJ, Lincoln P. Management of the pediatric postoperative cardiac surgery patient. Critical care nursing clinics of North America. 2005;17(4):405-416.

9. Gaies MG, Gurney JG, Yen AH, et al. Vasoactive-inotropic score as a predictor of morbidity and mortality in infants after cardiopulmonary bypass. Pediatr Crit Care Med. 2010;11(2):234-238.

10. Massé L, Antonacci M. Low cardiac output syndrome: identification and management. Crit Care Nurs Clin North Am. 2005;17(4):375-383.

11. Rao V, Ivanov J, Weisel RD, et al. Predictors of low cardiac output syndrome after coronary artery bypass. The Journal of Thoracic and Cardiovascular Surgery. 1996;112(1):38-51. 